\title{
Study of the Antibacterial Activity of Methanolic and Aqueous Extracts of Myrtus communis on Pathogenic Strains Causing Infection
}

\author{
Behrooz Alizadeh Behbahani, ${ }^{1}$ Farideh Tabatabaei Yazdi, ${ }^{1,}{ }^{*}$ Hamid Noorbakhsh, ${ }^{1}$ Fatemeh Riazi, ${ }^{2}$ Amir \\ Jajarmi, ${ }^{1}$ and Forouzan Tabatabaei Yazdi ${ }^{3}$ \\ ${ }^{1}$ Department of Food Sciences and Technology, Faculty of Agriculture, Ferdowsi University of Mashhad, Mashhad, IR Iran \\ ${ }^{2}$ Department of Food Sciences and Technology, Faculty of Agriculture, Urmia University, Urmia, IR Iran \\ ${ }^{3}$ Department of Animal Sciences, Faculty of Agriculture, Ferdowsi University of Mashhad, Mashhad, IR Iran \\ "Corresponding author: Farideh Tabatabaei Yazdi, Department of Food Sciences and Technology, Faculty of Agriculture, Ferdowsi University of Mashhad, Mashhad, IR Iran. \\ E-mail: tabatabai@um.ac.ir
}

Received 2014 July 25; Accepted 2014 November 29.

\begin{abstract}
Background: Medicine plants have been used as sources of medicine in virtually all cultures. During the last decade, the use of traditional medicine (TM) has been expanded globally and is gaining popularity.

Objectives: The antimicrobial activities of methanol and water extracts of Myrtus communis L. leaves were evaluated in this study.

Materials and Methods: In this experimental study, the tests were carried out using disk agar diffusion method at four extract concentrations $(5,10,15$ and $20 \mathrm{mg} / \mathrm{mL})$. The MICs and MBCs of the extracts of $M$. communis were determined by agar dilution method. Average results were reported as the mean and standard error (mean \pm SE) and SPSS-18 statistical software, oneway ANOVA followed by Turkey's test were used to do inter-group comparison, while considering $\mathrm{P} \leq 0.05$ as the significance level.

Results: Methanol extract of M. communis exhibited significant antibacterial activity in the concentration of $20 \mathrm{mg} / \mathrm{mL}(\mathrm{P} \leq 0.05)$ against Staphylococcus epidermidis and Enterococcus faecalis with a greater inhibition zone of $20 \mathrm{~mm}$, while a $14 \mathrm{~mm}$ zone of inhibition was observed in Escherichia coli and Shigella flexneri. The minimum inhibitory concentration (MIC) of the extracts ranged between 2 $\mathrm{mg} / \mathrm{mL}$ and $128 \mathrm{mg} / \mathrm{mL}$ while the minimum bactericidal concentration (MBC) ranged between $4 \mathrm{mg} / \mathrm{mL}$ and $256 \mathrm{mg} / \mathrm{mL}$.

Conclusions: The study showed that species, strains and concentrations of $M$. communis extract are of those factors that may influence the sensitivity of the tested bacteria. A significant correlation was observed between zone of inhibition and concentration of extract.
\end{abstract}

Keywords: Infection, Aqueous Extracts, Methanolic Extract, Myrtus communis

\section{Background}

The rediscovery of the connection between plants and health is responsible for the launching of new generations of multi-component botanical drugs, dietary supplements and plant-produced recombinant proteins [1]. Approximately 700 mono and poly-herbal preparations in the form of decoction, tincture, tablets and capsules from more than 100 plants are in clinical use [2].

Though the resistance development by microbes cannot be stopped, appropriate action will reduce the mortality and health care costs by using antibiotic resistant inhibitors of plant origin [3]. The increase in resistance of microorganisms due to multi-various use of commercial antimicrobial drugs has encouraged scientists all over the world to search for new antimicrobial substances from various antecedents comprising medicinal plants [4].

Myrtle (Myrtus communis L.) is a member of Mirtaceae family that grows spontaneously throughout the Mediterranean area [5].The plant is an ever green shrub or small tree, growing to 5 metres $(16 \mathrm{ft})$ tall. The entire leaf is, $3-5 \mathrm{~cm}$ long, with a fragrant essential oil. The leaves contain tannins, flavonoids such as quercetin, catechin and myricetin derivatives and volatile oils Myrtle occupies a prominent place in the writings of Hippocrates, Pliny, Dioscorides, Galen, and the Arabian writers. In several countries, particularly in Europe and China, there has been a tradition for prescribing this substance for sinus infections [6].

Infections are associated with intravascular devices (prosthetic heart valves, shunts, etc.) and also commonly occur in prosthetic joints, catheters, and large wounds. Catheter infections along with catheter-induced UTIs lead to serious inflammation and pus secretion. In these instances, urination is extremely painful. Septicemia and endocarditis are also diseases associated with Staphylococcus epidermidis [7]. Their symptoms run the gamut from fever, headache and fatigue to anorexia and dyspnea. Septicemia is especially prevalent resulting from neonatal infections, 
particularly in very low birth weights. Endocarditis is an infection of the heart valves and parts of the inside lining of the heart muscle. S. epidermidis is very likely to contaminate patient-care equipment and environmental surfaces, possibly explaining the high incidence of S. epidermidis in the hospital setting [8]. Several different serogroups of Shigella are described; Shigella flexneri belongs to group B. S. flexneri infections can usually be treated with antibiotics, although some strains have become resistant [9]. Enterococcus faecalis can and Escherichia coli cause endocarditis and bacteremia, urinary tract infections (UTI), meningitis, and other infections in humans [10].

\section{Objectives}

On the basis, the aim of this work was to investigate the possible inhibitory activity of Myrtus communis extracts against pathogenic strains causing infection.

\section{Materials and Methods}

This experimental study was conducted at industrial microbiology laboratory, department of food sciences and technology, Ferdowsi University of Mashhad in 2014.

\subsection{Media}

Mueller-Hinton agar and nutrient agar (DEFCO Laboratories, USA), peptone bacteriological (BDH Chemicals Ltd., England), tryptone soya broth and sodium chloride (East Anglia Chemicals, UK) were all obtained from the department of food sciences and technology, Ferdowsi University of Mashhad.

\subsection{Test Strains}

The following Gram (+) and Gram (-) bacteria were used for testing antibacterial activity. S. epidermidis ATCC 12228, E. faecalis ATCC 29212, E. coli ATCC29998 and S. flexneri ATCC12022 all American type culture collections were obtained from the microbiology department of Mashhad University of Medical Sciences, Mashhad.

\subsection{Collection and Preparation of the Plant Material}

The Myrtus communis were collected from countryside of Behbahan (Khuzestan Province, Iran). M. communis were dried in an open air protected from direct exposure to sunlight. The dried plant materials were separately powdered to suitable size [11]. The identity of each plant specimen was confirmed at the Herbarium, Ferdowsi University of Mashhad where a voucher specimen was deposited.

\subsection{Plant Extraction}

Two hundred grams of each powdered plant material were extracted with $80 \%$ methanol or water by maceration for 72 hours with frequent agitation and the resulting liquid was filtered (Whatman No. 3 filter paper, Whatman Ltd., England). Extraction was repeated five times and the filtrates of all portions were combined in one vessel. The organic solvent was removed by evaporation using Rota vapor (Rota-vapor R-205, England) at no more than $35^{\circ} \mathrm{C}$. The aqueous residues were hen placed in an oven at $35^{\circ} \mathrm{C}$ for about 72 hours to remove the water. The resulting dried mass was then powdered, packed into a glass vial and stored in a desiccator over silica gel until use [12].

\subsection{Suspension Preparation}

Fresh cultivated S. epidermidis ATCC 12228, E. faecalis ATCC 29212, E. coli ATCC29998 and S. flexneri ATCC12022 colonies were suspended in $10 \mathrm{~mL}$ of $0.80 \%$ normal saline. Suspension was mixed for 20 seconds with a vortex. Then its concentration was adjusted to $1.5 \times 10^{8} \mathrm{CFU} / \mathrm{mL}$ based on a standard 0.5 McFarland [13].

\subsection{Antimicrobial Susceptibility Test}

The ability of the various extracts to inhibit growth of clinical bacteria isolates was determined using the Agar disc diffusion method sterile filter paper discs; $7 \mathrm{~mm}$ in diameter were impregnated with each extract concentration and dried at $30^{\circ} \mathrm{C}$ in the static incubator. They were then carefully placed aseptically with a forceps on the surface of the Mueller Hinton agar (DEFCO Laboratories, USA), plates that were preinoculated with the 24 hours culture of bacteria and $0.1 \mathrm{~mL}$ suspension $\left(1.5 \times 10^{8} \mathrm{CFU} / \mathrm{mL}\right)$ of the bacteria isolates, respectively. The control antibiotics disc containing gentamycin solution was placed on each of the inoculated plates of Mueller Hinton agar. The plates were left on the bench undisturbed for few minutes, after which the bacterial plates were incubated at $37^{\circ} \mathrm{C}$ for 24 hours. The external diameters of visible zones of growth inhibition were measured after incubation $[14,15]$.

\subsection{Minimum Inhibitory Concentration (MIC)}

The minimum inhibitory concentration of extracts were determined by an agar dilution method according to the national committee for clinical laboratory standard (NCCLS) guidelines using a multipoint replicator and delivering $0.3 \mathrm{~mL}$ of standardized microbial suspension. The final concentration of extracts in the medium ranging was from $2 \mathrm{mg} / \mathrm{mL}$ to $256 \mathrm{mg} / \mathrm{mL}$. The plates were incubated at $37^{\circ} \mathrm{C}$ for 18 - 24 hours and the MIC was defined as the lowest concentration of extracts inhibiting the visible growth. All determinations were performed in duplicate and growth control consisting of $\mathrm{MH}$ medium was included [16]. 


\subsection{Minimum Bactericidal Concentration (MBC)}

Cells from the plate showing no growth were sub cultured on nutrient agar plates to determine whether the inhibition was reversible or permanent. MBC was determined as the highest dilution (lowest concentration) at which no growth occurred on the plates [17].

\subsection{Statistical Analysis}

Average results were reported as the mean and standard error (mean \pm SE) and SPSS-18 statistical software, one way ANOVA followed by Turkey's test were used to do intergroup comparison, while considering $\mathrm{P} \leq 0.05$ as the significance level.

\section{Results}

This study reports the antimicrobial activity of 4 concentrations of $M$. communis against S. epidermidis, E. faecalis, E. coli and S. flexneri. The results antimicrobial effects of methanolic and aqueous M. communis extracts, by "the agar diffusion method" were presented in Tables 1 and Figure 1. In this study, aqueous extract showed no inhibition against $E$. coli and S. flexneri bacteria tested at $5 \mathrm{mg} / \mathrm{mL}$ concentrations.

\section{Discussion}

The diameter of inhibition zone in methanol extract is higher than aqueous extract. On the contrary, statistical analysis using Turkey's test analysis showed that there are no significant differences between methanol extract and aqueous extract used. The discs containing $20 \mathrm{mg} / \mathrm{mL}$ of methanolic extract showed the highest mean zones of Inhibition against $S$. epidermidis, E. faecalis, E. coli and $S$. flexneri, while the discs containing $5 \mathrm{mg} / \mathrm{mL}$ showed the lowest inhibitory zones. Methanolic extract of $M$. communis showed the highest mean zones of inhibition $(20 \pm 0.28$ $\mathrm{mm}$ ) at $20.0 \mathrm{mg} / \mathrm{mL}$ on S. epidermidis. Aqueous M. communis extract showed the highest mean zones of inhibition (18 $\pm 0.28 \mathrm{~mm}$ ) at $20 \mathrm{mg} / \mathrm{mL}$ on S. epidermidis.

Turkey's test range tests showed significant difference among the mean diameter inhibition zones for the ethanolic stem extracts of M. communis. The findings in this study pointed out that the higher the concentrations of the extracts, the higher the sensitivities of S. epidermidis, E. faecalis, E. coli and S. flexneri to the methanolic extract of $M$. communis as evidenced by the increased size of the bacterial growth inhibition zones. Since ancient civilization, natural sources especially plants are used as medicinal therapy because they contain several components which are believed to cure various infectious diseases. The biodiversity of plants provides an important source of chemical compounds, which have much therapeutic application such as antiviral, antibacterial, antifungal and anticancer activities [18]. Therefore, the aim of this study was to investigate the possible inhibitory activity of M. communis extracts against pathogenic strains causing infection.

Thus, exhibiting concentration dependent activity and these results are in conformity with Chandrasekaran et al. [19] and Chomnawang et al. [20]. Iauk et al. [21] also showed that the higher the concentrations of the Vernonia amygdalina, the larger the diameter of the bacterial growth inhibition zones.

The MIC of methanolic extract of M. communis for S. epidermidis, E. faecalis, E. coli and S. flexneri were 2, 4, 16 and $32 \mathrm{mg} / \mathrm{mL}$, respectively. However, MIC of the aqueous extract of M. communis for S. epidermidis, E. faecalis, E. coli and S. flexneri were 4, 16, 64 and $128 \mathrm{mg} / \mathrm{mL}$, respectively. The mechanism of action of extract plant and essential oil and their components as antimicrobials has not been fully elucidated. This is complicated by the fact that there are a large number of chemical compounds present in extract and EOs and often they are all needed for antibacterial activity and the extract and EOs does not seem to have a specific cellular target. Thus the antimicrobial mechanism of extract and EOs may not be attributable to one specific mechanism, but rather there may be several targets in the cell. Most of the focus on antimicrobial mechanisms for extract and EOs has been on the cell membrane and targets interconnected with the membrane. For bioactivity, the extract and EOs pass through the cell wall and cytoplasmic membrane [22].

The MBC of methanolic extract of M. communis for S. epidermidis, E. faecalis, E. coli and S. flexneri were 4, 8, 32 and 64 $\mathrm{mg} / \mathrm{mL}$, respectively. But MBC of aqueous extract of M. communis for S. epidermidis, E. faecalis, E. coli and S. flexneri were $8,32,128$ and $256 \mathrm{mg} / \mathrm{mL}$, respectively. In general, among the tested microbial strains, S. epidermidis were found to be more sensitive to many of the test agents than E. faecalis, E. coli and S. flexneri.

The antibacterial activity was more pronounced on the Gram (+) bacteria (S. epidermidis and E. faecalis) than the Gram (-) bacteria (E. coli and S. flexneri). The reason for the difference in sensitivity between Gram (+) and Gram (-) bacteria might be ascribed to the differences in morphological constitutions between these microorganisms, Gram (-) bacteria having an outer phospholipidic membrane carrying the structural lipopolysaccharide components [23]. This makes the cell wall impermeable to antimicrobial chemical substances. The Gram (+) bacteria on the other hand, is more susceptible having only an outer peptidoglycan layer which is not an effective permeabil- 
Table 1. Average Diameter (mm) of Microbial Free Zone Area of Aqueous and Methanolic Myrtus communis Extracts Concentrations on Staphylococcus epidermidis, Enterococcus faecalis, Escherichia coli and Shigella flexneri (Disk Agar Diffusion Method)

\begin{tabular}{|c|c|c|c|c|}
\hline \multirow[t]{2}{*}{ Type of Extract } & \multicolumn{4}{|c|}{ The Concentration of Myrtus communis Extracts, $\mathbf{m g} / \mathbf{m L}^{\mathrm{a}}$} \\
\hline & 5 & 10 & 15 & 20 \\
\hline \multicolumn{5}{|c|}{ Aqueous, microorganism } \\
\hline S. epidermidis & $9.00 \pm 0.54$ & $12.40 \pm 0.50$ & $16.00 \pm 0.52$ & $18.00 \pm 0.28$ \\
\hline E. faecalis & $8.00 \pm 0.52$ & $11.10 \pm 0.54$ & $15.80 \pm 0.54$ & $17.30 \pm 0.28$ \\
\hline E. coli & - & $8.20 \pm 0.52$ & $10.10 \pm 0.28$ & $12.30 \pm 0.50$ \\
\hline S. flexneri & - & $7.20 \pm 0.54$ & $9.40 \pm 0.28$ & $12.00 \pm 0.50$ \\
\hline \multicolumn{5}{|c|}{ Methanolic,microorganism } \\
\hline S. epidermidis & $10.80 \pm 0.58$ & $14.00 \pm 0.54$ & $17.80 \pm 0.54$ & $20.0 \pm 0.28$ \\
\hline E. faecalis & $9.90 \pm 0.58$ & $14.30 \pm 0.50$ & $16.40 \pm 0.54$ & $19.70 \pm 0.28$ \\
\hline E. coli & $8.00 \pm 0.54$ & $10.00 \pm 0.57$ & $12.10 \pm 0.54$ & $14.00 \pm 0.58$ \\
\hline S. flexneri & $7.70 \pm 0.58$ & $9.80 \pm 0.54$ & $12.00 \pm 0.28$ & $13.60 \pm 0.57$ \\
\hline
\end{tabular}

${ }^{\mathrm{a}}$ Values are expressed as means $\pm \mathrm{SD} ; \mathrm{n}=3$.

Table 2. Minimum Inhibitory Concentration (MIC) of Aqueous and Ethanolic Extract of Myrtus communis on Staphylococcus epidermidis, Enterococcus faecalis, Escherichia coli and Shigella flexneri

\begin{tabular}{|c|c|c|c|c|c|c|c|c|c|c|}
\hline \multirow[t]{2}{*}{ Type of Extract } & \multicolumn{10}{|c|}{ Concentration, $\mathbf{m g} / \mathbf{m L}^{\mathbf{a}}$} \\
\hline & 2 & 4 & 8 & 16 & 32 & 64 & 128 & 256 & Negative & Positive \\
\hline \multicolumn{11}{|c|}{ Aqueous, bacteria species } \\
\hline S. epidermidis & + & + & . & . & . & . & . & . & - & + \\
\hline E. faecalis & + & + & + & + & . & . & . & . & - & + \\
\hline E. coli & + & + & + & + & + & + & . & . & . & + \\
\hline S.flexneri & + & + & + & + & + & + & + & - & - & + \\
\hline S. epidermidis & . & . & . & - & - & - & . & . & . & + \\
\hline S.flexneri & + & . & . & - & - & . & - & . & - & + \\
\hline \multicolumn{11}{|l|}{ Methanolic } \\
\hline S. epidermidis & + & + & + & . & . & - & - & . & - & + \\
\hline E. faecalis & + & + & + & + & . & . & . & . & . & + \\
\hline
\end{tabular}

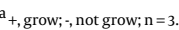

Table 3. Minimum Bactericidal Concentration (MBC) of Aqueous and Ethanolic Extract of Myrtus communis on Staphylococcus epidermidis, Enterococcus faecalis, Escherichia coli and Shigella flexneri

\begin{tabular}{|c|c|c|c|c|c|c|c|c|c|c|}
\hline \multirow[t]{2}{*}{ Type of Extract } & \multicolumn{10}{|c|}{ Concentration, $\mathbf{m g} / \mathrm{mL}^{\mathbf{a}}$} \\
\hline & 2 & 4 & 8 & 16 & 32 & 64 & 128 & 256 & Negative & Positive \\
\hline \multicolumn{11}{|c|}{ Aqueous, bacteria species } \\
\hline S. epidermidis & + & + & . & - & - & - & - & - & - & + \\
\hline E. faecalis & + & + & + & - & - & - & - & - & - & + \\
\hline E. coli & + & + & + & + & + & + & . & . & . & + \\
\hline S.flexneri & + & + & + & + & + & - & - & - & - & + \\
\hline S. epidermidis & + & - & . & - & - & - & - & - & - & + \\
\hline E.faecalis & + & + & . & - & - & - & $\cdot$ & - & - & + \\
\hline \multicolumn{11}{|l|}{ Methanolic } \\
\hline E. coli & + & + & + & + & - & - & - & - & - & + \\
\hline S.flexneri & + & + & + & + & + & . & . & . & . & + \\
\hline
\end{tabular}


A

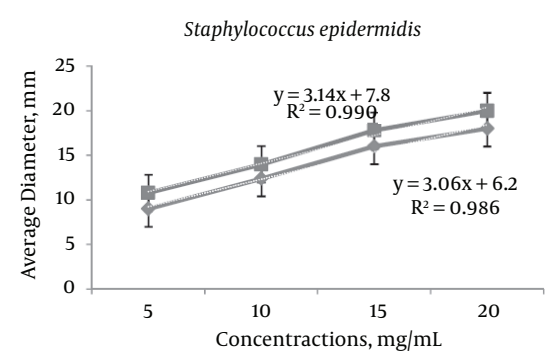

C

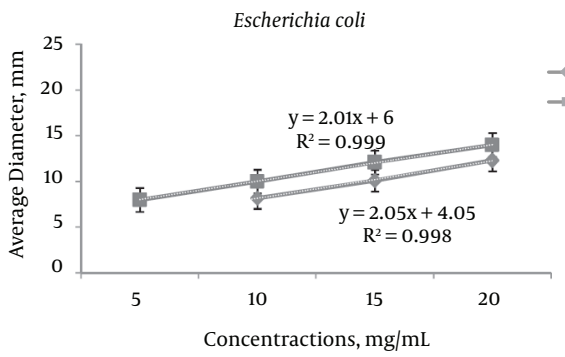

B

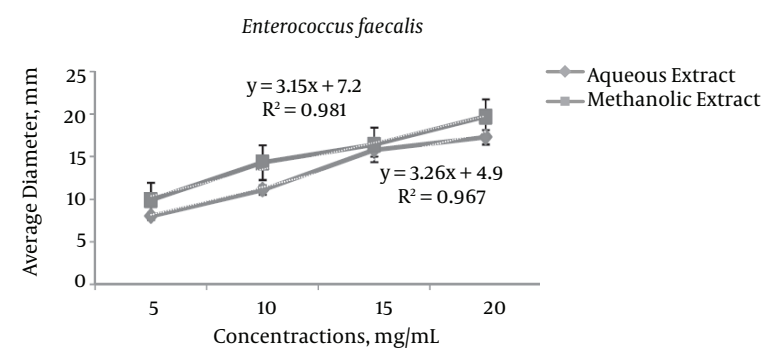

D

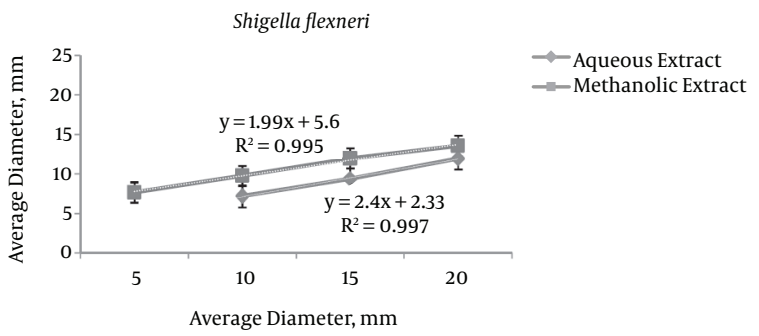

Figure 1. Antimicrobial Activity of Methanolic and Aqueous at Different Concentration of Myrtus communis Leaves Extracts on A, Staphylococcus epidermidis, B, Enterococcus faecalis, C, Escherichia coli and D, Shigella flexneri

ity barrier. Therefore, the cell walls of Gram (-) organisms which are more complex than the Gram (+) ones act as a diffusional barrier and making them less susceptible to the antimicrobial agents than are Gram (+) bacteria. In spite of this permeability differences, however, some of the extracts have still exerted some degree of inhibition against Gram (-) organisms as well [24].

Rasooli et al. [25] reported the major components M. communis were $\alpha$-pinene (29.4\%), limonene (21.2\%), 1 , 8-cineole (18\%), linalool (10.6\%), linalyl acetate (4.6\%) and $\alpha$-terpineole (3.1\%). This study favors the report that the essential oils with high monoterpenes hydrocarbons are very active against microorganisms. These secondary metabolites exert antimicrobial activity through different mechanisms. Tannins form irreversible complexes with proline rich protein, resulting in the inhibition of cell protein synthesis, flavonoids complex with extracellularsoluble proteins and bacterial cell wall proteins, while lipophilic flavonoids disrupt microbial cells membranes [26].

Mert et al. [27] investigated the antimicrobial activities of n-hexane, methanol, ethanol, ethyl acetate and water extracts of M. communis L. leaves against E. coli, S. aureus, S. epidermidis, Salmonella typhimurium, Enterobacter cloacae, E. faecalis and P. aeruginosa as bacteria and Candida albicans as yeast like fungi by disc diffusion method. Results showed all the extracts inhibited the growth of E. coli, S. epidermidis, S. typhimurium and P. aeruginosa. The growth of $E$. coli was only inhibited by the methanol extract. None of the tested extracts showed activity against E. cloacae, E. faecalis and C. albicans.

On the basis of the above, results showed that methanol extract of $M$. communis exhibited a greater inhibition compared with aqueous extract. AlizadehBehbahani et al. [28] reported that the most of the antimicrobial active compounds were soluble in polar solvent such as ethanol instead of water. Koffi-Nevry et al. [29] the effect of Capsicum annuum and Capsicum frutescens methanol and aqueous extracts on selected bacteria ( $S$. aureus, S. typhimurium, Vibrio cholerae, Pseudomonas aeruginosa, E. coli, and S. dysenteriae) were investigated. Both extracts were found to be effective against V. cholerae, S. aureus and S. typhimurium, while methanol extracts showed the greatest effect. The extract from Capsicum annuum showed a higher antibacterial activity than the one from Capsicum frutescens. The MIC of methanol and aqueous extracts were $0.2 \mathrm{mg} / \mathrm{mL}$ and $0.25 \mathrm{mg} / \mathrm{mL}$, respectively. $\mathrm{MBC}$ values of both extracts ranged from 1 to $2.5 \mathrm{mg} / \mathrm{mL}$, this result is consistent with the findings of this study. This was also reported by Parekh et al. [30], the aqueous and ethanolic extracts of Launaea procumbensRoxb. (Labiateae), Vitis vinifera L. (Vitaceae) and Cyperus rotundus L. (Cyper- 
aceae) were evaluated for antimicrobial activity against clinically important bacteria viz. Ethanolic extracts were more potent than aqueous extracts and activity were concentration dependent, this result is consistent with the findings of this study.

In this study, a limit of our research is the small amount of the extract that did not allow performing the MIC towards all the strains used. These data are encouraging even if further additional "in vitro" testing and large clinical studies are necessary to verify the potential use of the extract of M. communis as antibacterial drug. Given the excellent results obtained in this study, we would expand the research with further studies, to value the possible cytotoxic effects, and eventually to perform tests using "in vivo" mouse model.

\section{Acknowledgments}

The authors wish to express their profound gratitude and thank sincerely to research's deputy of Ferdowsi University of Mashhad for providing the cost of this project with code 2/16135. The authors also wish to express their profound gratitude to Ms. Afsharian who helped us regarding the experiments and Mr. Amin Mehraeen for his helps in preparing samples.

\section{Footnotes}

Authors' Contribution: All authors had equal role in design, work, statistical analysis and manuscript writing.

Funding/Support: Ferdowsi University of Mashhad.

\section{References}

1. Raskin I, Ribnicky DM, Komarnytsky S, Ilic N, Poulev A, Borisjuk N, et al. Plants and human health in the twenty-first century. Trends Biotechnol. 2002;20(12):522-31. doi:10.1016/S0167-7799(02)02080-2.

2. Chakraborthy G. Antimicrobial activity of the leaf extracts of Calendula officinalis (Linn). J Herb Med Toxicol. 2008;2(2):65-6.

3. Akinjogunla O, Adegoke A, Udokang I, Adebayo-Tayo B. Antimicrobial potential of Nymphaea lotus (Nymphaeaceae) against wound pathogens. J Med Plants Res. 2009;3(3):138-41.

4. Akinjogunla O, Adenugba I, Jumbo O. In-vitro antibacterial evaluation of ethanolic stem crude extracts of anacardium occidentale linn.(anacardiaceae) on streptococcus mutans associated with dental caries. Sci J Microbiol. 2012;1(3):71-81.

5. Mansouri S, Foroumadi A, Ghaneie T, Najar AG. Antibacterial activity of the crude extracts and fractionated constituents of Myrtus communis. Pharm Biol. 2001;39(5):399-401. doi: 10.1076/phbi.39.5.399.5889.

6. Yadegarinia D, Gachkar L, Rezaei MB, Taghizadeh M, Astaneh SA, Rasooli I. Biochemical activities of Iranian Mentha piperita L. and Myrtus communis L. essential oils. Phytochemistry. 2006;67(12):1249-55. doi: 10.1016/j.phytochem.2006.04.025. [PubMed:16777154].

7. Gill SR, Fouts DE, Archer GL, Mongodin EF, Deboy RT, Ravel J, et al. Insights on evolution of virulence and resistance from the complete genome analysis of an early methicillin-resistant Staphylococcus aureus strain and a biofilm-producing methicillin-resistant
Staphylococcus epidermidis strain. J Bacteriol. 2005;187(7):2426-38. doi: 10.1128/JB.187.7.2426-2438.2005. [PubMed: 15774886].

8. Otto M. Staphylococcus epidermidis-the 'accidental' pathogen. Nat Rev Microbiol. 2009;7(8):555-67. doi: 10.1038/nrmicro2182. [PubMed: 19609257].

9. Sperandio B, Regnault B, Guo J, Zhang Z, Stanley SJ, Sansonetti PJ, et al Virulent Shigella flexneri subverts the host innate immune response through manipulation of antimicrobial peptide gene expression. $J$ Exp Med. 2008;205(5):1121-32. doi: 10.1084/jem.20071698. [PubMed 18426984].

10. Werner G, Gfrorer S, Fleige C, Witte W, Klare I. Tigecycline-resistant Enterococcus faecalis strain isolated from a German intensive care unit patient. J Antimicrob Chemother. 2008;61(5):1182-3. doi: 10.1093/jac/dkn065. [PubMed: 18285315].

11. Tasdelen Fisgin N, Tanriverdi Cayci Y, Coban AY, Ozatli D, Tanyel E, Durupinar B, et al. Antimicrobial activity of plant extract Ankaferd Blood Stopper. Fitoterapia. 2009;80(1):48-50. doi: 10.1016/j.fitote.2008.09.006. [PubMed: 18930120].

12. Igbinosa O, Igbinosa E, Aiyegoro O. Antimicrobial activity and phytochemical screening of stem bark extracts from Jatropha curcas (Linn). Afr J Pharm Pharmacol. 2009;3(2):058-62.

13. Estevinho L, Pereira AP, Moreira L, Dias LG, Pereira E. Antioxidant and antimicrobial effects of phenolic compounds extracts of Northeast Portugal honey. Food Chem Toxicol. 2008;46(12):3774-9. doi 10.1016/j.fct.2008.09.062. [PubMed: 18940227].

14. Nostro A, Germano MP, D'Angelo V, Marino A, Cannatelli MA. Extraction methods and bioautography for evaluation of medicinal plant antimicrobial activity. Lett Appl Microbiol. 2000;30(5):379-84. [PubMed: 10792667].

15. Gulluce M, Sokmen M, Daferera D, Agar G, Ozkan H, Kartal N, et al In vitro antibacterial, antifungal, and antioxidant activities of the essential oil and methanol extracts of herbal parts and callus cultures of Satureja hortensis L. J Agric Food Chem. 2003;51(14):3958-65. doi 10.1021/jf0340308. [PubMed:12822930].

16. Lambert RJ, Skandamis PN, Coote PJ, Nychas GJ. A study of the minimum inhibitory concentration and mode of action of oregano essential oil, thymol and carvacrol. J Appl Microbiol. 2001;91(3):453-62. [PubMed: 11556910].

17. Karaman I, Sahin F, Gulluce M, Ogutcu H, Sengul M, Adiguzel A. Antimicrobial activity of aqueous and methanol extracts of Juniperus oxycedrus L. J Ethnopharmacol. 2003;85(2-3):231-5. [PubMed: 12639746]

18. Okeke MI, Iroegbu CU, Eze EN, Okoli AS, Esimone CO. Evaluation of extracts of the root of Landolphia owerrience for antibacterial activity. JEthnopharmacol. 2001;78(2-3):119-27. [PubMed: 11694355].

19. Chandrasekaran $M$, Venkatesalu V. Antibacterial and antifungal activity of Syzygium jambolanum seeds. J Ethnopharmacol. 2004;91(1):1058. doi: 10.1016/j.jep.2003.12.012. [PubMed: 15036477].

20. Chomnawang MT, Surassmo S, Nukoolkarn VS, Gritsanapan W. Antimicrobial effects of Thai medicinal plants against acneinducing bacteria. J Ethnopharmacol. 2005;101(1-3):330-3. doi: 10.1016/j.jep.2005.04.038. [PubMed: 16009519].

21. Iauk L, Lo Bue AM, Milazzo I, Rapisarda A, Blandino G. Antibacterial activity of medicinal plant extracts against periodontopathic bacteria. Phytother Res. 2003;17(6):599-604. doi: 10.1002/ptr.1188. [PubMed: 12820224].

22. Basile A, Sorbo S, Giordano S, Ricciardi L, Ferrara S, Montesano D, et al Antibacterial and allelopathic activity of extract from Castanea sativa leaves. Fitoterapia. 2000;71:S110-6. doi: 10.1016/S0367-326X(00)00185-

23. Srinivasan D, Nathan S, Suresh T, Perumalsamy P. Antimicrobial activity of certain Indian medicinal plants used in folkloric medicine.J Ethnopharmacol. 2001;74(3):217-20. doi: 10.1016/S0378-8741(00)00345- 
24. Holetz FB, Pessini GL, Sanches NR, Cortez DA, Nakamura CV, Filho BP. Screening of some plants used in the Brazilian folk medicine for the treatment of infectious diseases. Mem Inst Oswaldo Cruz. 2002;97(7):1027-31. [PubMed: 12471432].

25. Rasooli I, Moosavi M, Rezaee M, Jaimand K. Susceptibility of microorganisms to Myrtus communis L. essential oil and its chemical composition. J Agric Sci Technol. 2010;4:127-33.

26. Rosato A, Vitali C, De Laurentis N, Armenise D, Antonietta Milillo M Antibacterial effect of some essential oils administered alone or in combination with Norfloxacin. Phytomedicine. 2007;14(11):727-32. doi 10.1016/j.phymed.2007.01.005. [PubMed: 17303397].

27. Mert T, Fafal T, Kivcak B, Ozturk H. Antimicrobial and cytotoxic activities of Myrtus communis L. Myrtus Communis L. J Faculty Pharm.
2008;37(3):191-9.

28. Alizadeh Behbahani B, Tabatabaei Yazdi F, Shahidi F, Mohebbi M. Antimicrobial activity of Avicennia marina extracts ethanol, methanol \& glycerin against Penicillium digitatum (citrus green mold). Sci J Microbiol. 2012;1(7):147-51.

29. Koffi-Nevry R, Kouassi KC, Nanga ZY, Koussémon M, Loukou GY. Antibacterial activity of two bell pepper extracts: Capsicum annuum L. and Capsicum frutescens. Int J Food Properties. 2012;15(5):961-71. doi: 10.1080/10942912.2010.509896.

30. Parekh J, Chanda S. In-vitro antimicrobial activities of extracts of Launaea procumbens roxb.(Labiateae), Vitis vinifera l.(Vitaceae) and Cyperus rotundus 1.(Cyperaceae. Afr J Biomed Res. 2006;9(2):89-93. 